\title{
Effect of Scanning Mode on Temperature Field and Interface Morphology of Laser Joining between CFRTP and TC4 Titanium Alloy
}

\section{Weiwen Chen}

Nanjing University of Aeronautics and Astronautics

\section{Xiqin Liu}

Nanjing University of Aeronautics and Astronautics

Hengchang Bu

Nanjing University of Aeronautics and Astronautics

\section{Feiyun Wang}

Nanjing University of Aeronautics and Astronautics

Jiebang Luo

Nanjing University of Aeronautics and Astronautics

Xiaohong Zhan ( $\triangle$ xiaohongzhan_nuaa@126.com)

Nanjing University of Aeronautics and Astronautics

\section{Research Article}

Keywords: Laser joining, Oscillating laser, CFRTP, Numerical simulation, Interface morphology, Joining strength

Posted Date: December 16th, 2021

DOI: https://doi.org/10.21203/rs.3.rs-1152079/v1

License: (9) This work is licensed under a Creative Commons Attribution 4.0 International License. Read Full License 


\section{Abstract}

Hybrid components composed of CFRTP (Carbon Fiber Reinforced Thermoplastic Polymer) and TC4 titanium alloy are increasingly applied in the aerospace field. The scanning mode has a significant influence on the quality of laser joining joint between CFRTP and TC4 titanium alloy. Therefore, the laser joining between TC4 titanium alloy with surface microgrooves and CFRTP has been implemented under oscillating laser joining mode and linear laser joining mode respectively in the present research. The temperature distribution is qualitatively explored based on the established mathematical model of laser joining between CFRTP and TC4 titanium alloy. The interface morphology and the joining strength of CFRTP/TC4 titanium alloy lap joints under oscillating laser joining and linear laser joining are compared. The results indicate that the simulated temperature distribution shows good agreement with the experimental result. Compared with linear laser joining, the oscillating laser joining weakens the heat concentration and creates a heating zone with larger area and more uniform temperature distribution. The interface morphology of laser joining CFRTP/TC4 titanium alloy joints with better resin filling and fewer bubble defects is obtained by oscillating laser joining due to the temperature variation of the form of unequal amplitude oscillations, whereas there are a large number of large-size bubbles in the filling resin and small-sized fusion gaps distributed at the interface with the linear laser scanning mode. By adopting the joining method with oscillating laser scanning mode, higher quality joints can be obtained.

\section{Introduction}

Due to the increasing demand in automotive and aerospace industries, the manufacture of hybrid components for lightweight construction has attracted extensive attention [1-3]. The hybrid components composed of composites and alloys can reduce product weight and improve the parts performance, which provide a solution to the problems of aircraft fuselage weight reduction, fuel consumption reduction and carrying capacity improvement. As a kind of fiber reinforced composites developed rapidly in recent years, Carbon Fiber Reinforced Thermoplastic Polymer (CFRTP) has attracted much attention in the aerospace field owing to its high specific strength, excellent specific modulus, short molding cycle, recyclability and weldability, and has been gradually expanded to be applied in structural parts of aircraft fuselages [4-6]. In addition, titanium alloy is a kind of crucial structural material applied in the aerospace industry, with high specific strength, good corrosion resistance, a wide range of operating temperatures, excellent processability and other high comprehensive performance and structural benefits $[7,8]$. With the continuous development of lightweight alloys and advanced composites in the aerospace field, the hybrid structure of composites and metal is bound to appear in some aircraft constructions in practical application. How to realize the effective connection of these two materials is a pressing problem to be solved in the aerospace field. Although the traditional mechanical connection technology is a mature and simple process, it requires drilling holes on the parts, which will cut off the fibers, thus affecting the service performance of carbon fiber reinforced composites structure, and the opening part will cause stress concentration and local reduction of strength [9]. Additional weight is also added due to the parts such as rivets and screws used in mechanical connections. Besides, adhesive bonding technology is also 
a common connection process between thermoplastic composites and metal, which is non-destructive and non-stress concentrated, but the adhesive applied in bonding technology shows a long curing cycle and is not friendly to the environment [10]. In recent years, a variety of new thermal connection methods have emerged. Among them, laser joining technology shows broad application prospects and great development potential in the connection between thermoplastic composites and metal due to its advantages of controllable heat input, non-contact, high efficiency and green environmental protection $[11,12]$.

However, the great difference in thermophysical properties between thermoplastic composites and metal sets up an obstacle to achieve the high-quality combination of them by laser joining technology. In order to improve the combination effect between thermoplastic composites and metal, a great quantity of research has been carried out. Jung et al. [13-15] studied the laser joining process of stainless steel, tozinc-coated steel and aluminium alloy with carbon fiber reinforced plastic respectively and analyzed the influence of joining parameters on the quality of the joint. Bergman et al. [16] analyzed the influence of laser power and laser irradiation sequence on the strength of laser joining joints between glass fiber reinforced thermoplastic polymer and cold rolled steel sheets. Amend et al. [17] proposed a novel approach for laser joining of thermoplastic-metal hybrids utilizing a combination of mono- and polychromatic radiation. In this work, hybrid joints of aluminum and technical thermoplastics (PC, PA6, PA66-GF30) were studied. Rodríguez et al. [18] performed laser joining experiments on dual phase steel and fiber-reinforced polyamide, and discussed the effect of different microstructures, in particular geometry and cavity aspect ratio, on the tensile-shear mechanical performance of the joint, with the assistance of a finite element model to ensure the required interface temperature. Zhang et al. [19] used fiber laser to realize the connection between A7050 aluminum alloy and carbon fiber reinforced plastic, focused on evaluating the effect of laser Surfi-Sculpt process on the shear strength of A7050 and CFRP joint, and studied the tensile failure mechanism of the dissimilar joint. Lambiase et al. [20, 21] adopted laser-assisted direct joining methods to connect 304 stainless steel/polycarbonate and carbon fiberreinforced polycarbonate/polycarbonate, investigated the effect of laser power and scanning speed on the quality of laser direct connection joint and analyzed the size and distribution of interfacial defects. K. Van Der Straeten et al. [22] generated random self-organizing micro- and nanostructures with ultrashort pulsed laser radiation on stainless steel sample and investigated the strength of the joint between stainless steel and glass-fiber-reinforced and non-reinforced thermoplastics (PP) for three different load directions. Jiao et al. [23] carried out experiments with different joining parameters on fiber laser welding system to explore the mechanism of CFRTP/stainless steel joining and explored the influence of parameters such as laser power, joining speed and clamper pressure on the stainless steel surface thermal defect and the joint strength. Tao et al. [24] adopted laser welding technology to connect short carbon fiber reinforced polyphenylene sulfide (SCF/PPS) and TC4 titanium alloy, and observed that bubbles generated due to the decomposition of matrix resin, which could be eliminated by appropriate adjustment of the process parameters. Su et al. [25] researched laser joining of carbon fiber reinforced polyether ether ketone to titanium alloy and provided some data that the shear strength of the joint tends to increase first and then decrease with the increase of defocus amount. 
Compared with experimental research, the changes of temperature and stress in the process of laser joining between metal and thermoplastic composites can be more intuitively reflected by simulation technology. Hussein et al. [26] established a three-dimensional ab-initio model, it could predict the thermal distribution of laser direct joining processes between Polymethylmethacrylate (PMMA) and stainless steel 304, and compared the simulated temperature distribution with the thermal test results. The results showed that the finite element model could accurately predict the temperature distribution in the connection process. F.Lambiase et al. [27] proposed a procedure for calibrating and validating a Finite Element (FE) model of the thermal field of laser-assisted metal to polymer direct joining. Jiao et al. [28, 29] established a mathematical model of CFRTP/stainless steel laser joining, simulated the temperature distribution in the process of laser joining by finite element method, and analyzed the relationship between the depth and width of molten pool and the process parameters of laser joining. Then, the calculation method of contact thermal conductivity was proposed based on experiments, and a threedimensional thermal contact model for laser joining of CFRTP and stainless steel was established to solve the temperature field in the laser joining process.

The etching of microstructure on metal surface greatly increases the contact area between resin and metal, and creates a mechanical connection structure at the joint interface, thus effectively improving the quality of the joint [30]. Heckert et al. [31] pretreated the surface of aluminum alloy by laser etching technology and realized the connection between aluminum alloy and glass fiber reinforced thermoplastic composites by laser heat conduction connection technology. Rodríguez-Vidal et al. [32] studied the surface modification pretreatment on laser direct joining of glass fiber reinforced polyamide to steel and produced the metal micro-structuring by two different laser sources (nanosecond pulses and continuous wave) in order to study the effect of different groove geometries on the failure force of joint under tensileshear tests. Wang et al. [3] carried out a surface texturing treatment with continuous wave fiber laser on Ti6Al4V to improve joint strength through the formation of interlock structures between Ti6Al4V and PA66-GF30. In addition to etching microstructure on metal surface, swing the laser beam can reduce the formation of pores during laser joining, thereby enhancing the strength of the joint [33]. Fetzer et al. [34] investigated the influence of the spatial beam oscillation on the dynamics of the capillary and the mechanism leading to an increased or reduced generation of process pores for deep penetration laser beam welding of the aluminum alloy AIMgSi. The weld seams were found to be virtually free from porosity by applying a circular beam oscillation.

At present, the comparison between oscillating laser joining and linear laser joining for CFRTP and TC4 titanium alloy has been rarely reported. In this work, the laser joining is carried out on TC4 titanium alloy with surface microgrooves and CFRTP under oscillating laser joining mode and linear laser joining mode respectively. The temperature field is investigated by the established three-dimensional finite element model, followed by a study of the interface morphology and the joining strength of the corresponding CFRTP/TC4 titanium alloy lap joints.

\section{Modeling Details}




\subsection{Heat source model}

The selection of the heat source is critical to the accuracy of simulating the laser joining process. There are many kinds of laser heat source models, but the selection of heat source model should be considered in combination with the material and form of heat source. In the previous experiment, scholars have found that a better connection effect could be obtained by connecting CFRTP and metal with a large defocus swing laser [35]. Therefore, the temperature field of the connection process between CFRTP and TC4 titanium alloy under different laser scanning modes (linear, oscillating) will be simulated and discussed respectively. The schematic diagram of the laser joining process between CFRTP and TC4 titanium alloy is shown in Fig. 1, in which Fig. 1 (d) displays the trajectory of laser oscillation. During the connecting process of the CFRTP and TC4 titanium alloy single lap joint, the surface of titanium alloy is irradiated by the laser, which absorbs the laser energy, and then part of the titanium alloy melts to form a molten pool. When the heat is transferred to the interface bonding area between titanium alloy and CFRTP through heat conduction, the resin on the surface of CFRTP melts, and the molten resin flows into the grooves on the surface of TC4 titanium alloy under the pressure of the fixture. After the resin has cooled and solidified, there is a mechanical interlock between the microgroove structure on the surface of TC4 titanium alloy and the filling resin to realize the connection between CFRTP and titanium alloy. Through many times of exploration and analysis, the "Gaussian surface heat source + Gaussian cylindrical volumetric heat source" has been finally selected as the heat source model for the joining process, which could better reflect the actual shape of the molten pool formed by laser joining.

The Gaussian surface heat source represents the heating effect of plasma on the joints during the process of laser joining, and its heat flux density distribution expression is

$$
q_{x}(x, y)=\frac{\alpha Q_{s}}{\pi r_{x}^{2}} \exp \left[-\frac{\alpha\left(x^{2}+y^{2}\right)}{r_{x}^{2}}\right],
$$

where $Q_{S}$ refers to the effective power of Gaussian surface heat source, $a$ represents the heat flux concentration coefficient, and $r_{S}$ means the effective action radius of Gaussian surface heat source.

The Gaussian cylindrical volumetric heat source represents the penetration effect of laser beam on the surface of TC4 titanium alloy during laser joining, and its heat flux density distribution expression is

$$
q_{r}(x, y, z)=\frac{6 Q_{r}(H-\beta z)}{\pi r_{r}^{2} H^{2}(2-\beta)} \exp \left[-\frac{3\left(x^{2}+y^{2}\right)}{r_{r}^{2}}\right] .
$$

where $Q_{V}$ refers to the effective power of Gaussian cylindrical volumetric heat source, $\beta$ represents the attenuation coefficient, $r_{v}$ is the effective action radius of Gaussian cylindrical volumetric heat source, and $H$ means the effective action depth of Gaussian cylindrical volumetric heat source.

Fig. 2 illustrates the schematic diagram of composite heat source model of "Gaussian surface heat source + Gaussian cylindrical volumetric heat source". 


\subsection{Geometric model and Meshing}

The geometric model of laser joining structure between CFRTP and TC4 titanium alloy is established through modeling software. The dimensions of CFRTP and TC4 titanium alloy components are both 50 $\mathrm{mm} \times 25 \mathrm{~mm} \times 2 \mathrm{~mm}$. TC4 titanium alloy component is on the top, CFRTP component is on the bottom, the overlapping area is $20 \mathrm{~mm} \times 25 \mathrm{~mm}$, and the center distance of two weld seams is $7 \mathrm{~mm}$. Since the size of the groove is very small relative to the overall size of the component, it basically has no impact on the overall distribution of the temperature field, and sometimes there are problems such as sudden temperature change, so the groove is not set.

In order to have high accuracy and efficiency in the calculation process, the welding area of laser joining structure between CFRTP and TC4 titanium alloy is divided by transition mesh. The mesh model is shown in Fig. 3: Fine finite element mesh is adopted for the laser heating zones on the single lap surface; The mesh of the heat affected zones on the single lap surface is transformed by the fine mesh of the laser heating zones in a transition mode of 3: 1; Sparse mesh is applied for areas less affected by laser heat. After meshing, the total number of elements in this finite element model is 9700 and the total number of nodes is 11789 .

\subsection{Material properties}

In order to accurately simulate the laser bonding process, it is necessary to consider the changes of thermophysical parameters of materials at different temperatures. The physical parameters needed for the solution of the temperature field in this paper include density, specific heat capacity, thermal conductivity and melting point. The reinforcing phase of CFRTP component is T300 carbon fiber and the matrix is polyetheretherketone (PEEK) resin. The directional arrangement of carbon fibers in the resin matrix leads to the anisotropic thermophysical parameters of CFRTP. According to Fig. 4, the laying angle is $\pm 45^{\circ}$, and the thickness of single layer is $0.2 \mathrm{~mm}$. Based on the thermophysical parameters of PEEK and T300 carbon fibers, the thermophysical parameters of CFRTP are attained as listed in Table 1, where the $x$ direction is the fiber direction and the $z$ direction is perpendicular to the plane of the component. Fig. 5 shows the variation of thermophysical parameters of TC4 titanium alloy with temperature.

Table 1 Thermophysical parameters of CFRTP.

\begin{tabular}{|lll|}
\hline Density $\left(\mathrm{g} / \mathrm{cm}^{3}\right)$ & Specific heat capacity $(\mathrm{J} /(\mathrm{kg} \cdot \mathrm{K}))$ & Thermal conductivity $(\mathrm{W} /(\mathrm{m} \cdot \mathrm{K}))$ \\
\hline 1.53 & 1088 & $\mathrm{~K}_{x}=5.4 \unrhd \mathrm{K}_{y}=5.4 \unrhd \mathrm{K}_{z}=0.5$ \\
\hline
\end{tabular}

\subsection{Boundary condition and initial condition}

In this numerical simulation, the initial condition mainly refers to the initial environmental temperature. So combined with the actual test conditions, the initial environmental temperature is defined as $20^{\circ} \mathrm{C}$. In the process of laser joining, heat loss is mainly caused by radiation and convection between the workpiece 
surface and the surrounding environment, which mainly exists in the form of radiation loss. For the convenience of calculation, the radiation and convection coefficients are transformed into the total equivalent heat transfer coefficient with a value of $40 \mathrm{~W} /\left(\mathrm{m}^{2} \cdot{ }^{\circ} \mathrm{C}\right)$, and this boundary condition is loaded on all surfaces of the components.

\section{Experiment Details}

\subsection{Experimental materials}

In this study, carbon fiber reinforced polyetheretherketone composite (CF/PEEK) with thermoplastic resin PEEK as matrix and T300 carbon fiber as reinforcement is applied, which is hot-pressed into shape with hot-melt prepregs. Meanwhile, the specific chemical composition of TC4 titanium alloy is listed in Table 2.

\section{Table 2}

Chemical composition of TC4 titanium alloy (wt.\%).

\begin{tabular}{llllllllll|}
\hline Element & Al & V & Fe & C & N & H & O & Ti \\
\hline Content & $5.5-6.75$ & $3.5-4.5$ & 0.3 & 0.08 & 0.05 & 0.015 & 0.2 & Bal. \\
3.2. Experimental equipment & & & & &
\end{tabular}

Previous research has proved that designing microgrooves on the surface of titanium alloy can effectively improve the joining strength of CFRTP/titanium alloy laser joining joint [30]. In the process of laser joining, the heat of laser beam is transferred to the interface area between titanium alloy and CFRTP, and the molten resin on the surface of CFRTP flows into the microgrooves on the surface of titanium alloy under the action of fixture pressure. After cooling and solidification of resin, the interlocking effect is formed, which greatly enhances the mechanical joining strength.

The surface microgrooves of TC4 titanium alloy are processed by pulse laser in advance, and the laser power $P_{t}$ is $50 \mathrm{~W}$, the efficiency is $95 \%$, the repetition frequency is $50 \mathrm{kHz}$, the scanning speed is 1000 $\mathrm{mm} / \mathrm{s}$. The depth of micro grooves can be controlled by adjusting the repeated processing times of pulsed laser scanning. In addition, the processing morphology area and distribution density of micro grooves are controlled by adjusting the width and spacing of grooves. Through the exploration of previous experiments, the optimal combination of dimensional parameters has been obtained: the groove depth (h) is $0.35 \mathrm{~mm}$ (repeated processing times are 120 times), the groove width (a) is $0.5 \mathrm{~mm}$, and the groove spacing (b) is $1.8 \mathrm{~mm}$. Fig. 6 presents the laser processing process of TC4 titanium alloy surface microgrooves in detail.

Considering the single lap structure of CFRTP/TC4 titanium alloy, two different joining processes, linear laser joining and oscillating laser joining, are adopted. The laser equipment adopted in the laser joining 
experiment is YLS-10000 continuous fiber laser produced by IPG Company of Germany, with a maximum output power of $10000 \mathrm{~W}$ and a wavelength of $1070 \pm 5 \mathrm{~mm}$. In the laser joining process, KUKA60 sixaxis welding robot produced by KUKA Company of Germany is adopted, with a maximum working radius of $2033 \mathrm{~mm}$ and a repetition accuracy of $\pm 0.05 \mathrm{~mm}$. The laser joining process of CFRTP/TC4 titanium alloy is illustrated in Fig. 7, and the above experimental equipment can be seen through it.

\section{Simulation Results Of Temperature Field}

In the previous experiments, it has been found that in the joining of CFRTP and TC4 titanium alloy, the connection strength of two weld seams is higher than that of a single weld seam, so two weld seams are evenly distributed in the overlapping part of CFRTP and TC4 titanium alloy. It should be noted that the following contents related to weld seams refer to the first weld seam. In this paper, the oscillating laser joining mode is realized by setting the laser joining scanning path, to explore the influence of the two connection modes of linear laser joining and oscillating laser joining on the evolution and distribution of the temperature field. For the laser joining between CFRTP and TC4 titanium alloy, the optimal process parameters are taken for numerical calculation, as provided in Table 3.

\section{Table 3}

Laser joining process parameters.

\begin{tabular}{|c|c|c|c|c|}
\hline $\begin{array}{l}\text { Laser power } \\
\text { (W) }\end{array}$ & $\begin{array}{l}\text { Welding speed } \\
(\mathrm{m} / \mathrm{s})\end{array}$ & $\begin{array}{l}\text { Defocus amount } \\
(\mathrm{mm})\end{array}$ & $\begin{array}{l}\text { Frequency } \\
(\mathrm{Hz})\end{array}$ & Swing amplitude (mm) \\
\hline 2000 & 0.015 & +18 & 100 & 2 \\
\hline
\end{tabular}

Figure 8 compares the simulated results by adopting the composite heat source model of "Gaussian surface heat source + Gaussian cylindrical volumetric heat source" with the experimental results, and the gray area is the area where the temperature is higher than $1655^{\circ} \mathrm{C}(\mathrm{TC} 4$ titanium alloy melting temperature), that is, the molten pool area of titanium alloy. It is evident from Figure 8 that the molten pool profile obtained by oscillating laser joining simulation and linear laser joining simulation is in good agreement with the actual weld seam fusion line, which also proves that the finite element model adopted can well simulate the laser joining process between CFRTP and TC4 titanium alloy. It can also be perceived from the figure that the molten pool width of oscillating laser joining is $3.66 \mathrm{~mm}$ and the molten pool depth is $1.06 \mathrm{~mm}$, while the molten pool width of linear laser joining is $2.95 \mathrm{~mm}$, which is narrower than the former, and the molten pool depth is not much different from the former, which is 1.05 $\mathrm{mm}$. It can be concluded that the oscillating laser increases the absorption rate of laser energy by TC4 titanium alloy. With the increase of the action area of the oscillating laser on the base material, the molten pool width is increased, and the stirring effect of the oscillating laser makes the heat distribution of the whole weld seam uniform, resulting in a stable and wider molten pool. 
Peek resin is attached to the surface of CFRTP composites, whose melting point is $343^{\circ} \mathrm{C}$ and the thermal decomposition temperature is $520^{\circ} \mathrm{C}$. Therefore, it is specified that the interface fusion zone includes resin melting zone and resin decomposition zone, wherein the resin melting zone is the area with a temperature between $343^{\circ} \mathrm{C}$ and $520{ }^{\circ} \mathrm{C}$ in the interface fusion zone, and the resin decomposition zone is the gray area with a temperature higher than $520{ }^{\circ} \mathrm{C}$ in the interface fusion zone, as shown in Fig. 9 (a) and (b), which presents the simulated interface fusion zone at $t=0.285 \mathrm{~s}$. Under oscillating laser joining, the temperature in some areas of CFRTP exceeds $343{ }^{\circ} \mathrm{C}$, and the peek resin matrix melts in this resin melting zone, filling the microgrooves on the surface of TC4 titanium alloy under pressure and the lap gap between two components, thus realizing the reliable connection between CFRTP and TC4 titanium alloy. Under linear laser joining, the temperature in some areas of CFRTP exceeds $520{ }^{\circ} \mathrm{C}$, and the peek resin matrix in this high-temperature zone undergoes thermal decomposition, resulting in defects such as bubbles and incomplete fusion at the interface, which reduces the area of effective connection area and affects the joining quality of the joint. It can be clearly found from Fig. 9 (c), (d) and (e) that there is little difference in the area of resin melting zone between the two laser scanning modes, and slightly more resin is melted by oscillating laser joining, but the width of resin melting zone under linear laser joining is much smaller due to the existence of resin decomposition zone. The width of the interface fusion zone is almost the same in the two laser scanning modes, and the interface fusion zone produced by linear laser joining is deeper. Through comparison, it is found that the oscillating laser can weaken the heat concentration during laser joining, so as to reduce the defects such as bubbles and incomplete fusion. But in the case of linear laser joining, there is less molten resin at the interface and a large number of bubbles are generated, leading to complex heat flow behavior.

Due to the limitation of the numerical simulation software used, the temperature distribution of the CFRTP interface cannot be viewed directly. Therefore, the temperature distribution of the titanium alloy surface during laser joining is studied to indirectly reflect the temperature distribution of the CFRTP interface. For two different laser modes, the temperature variation of three nodes $a, b$ and $c$ in the vertical direction of weld center are selected, and the distance between node $a$ and $b$ is $1.5 \mathrm{~mm}$, the distance between node $b$ and $c$ is $1 \mathrm{~mm}$. The thermal cycle curve of each node is displayed in Fig. 10 (c) and (d). When the oscillating laser heat source approaches the nodes, the temperature at the nodes gradually rises in the form of unequal amplitude oscillations due to the oscillating scanning mode of the laser, and after reaching the maximum temperature, the temperature at the nodes gradually decreases in the form of unequal amplitude oscillations. The farther away from the weld center, the weaker the oscillation effect, and there is a small difference in the time of maximum temperature at each node due to the varied relative position to the heat source. When the linear laser heat source is adopted, the temperature at each node rises and falls in a smooth curve. Comparing the two figures, we can find that the maximum temperature of node $a$ in Fig. 10 (c) is lower than that of node $a$ in Fig. 10 (d), while the opposite is true for nodes $b$ and $c$. The reason is that the oscillating scanning mode evenly disperses the laser energy, and as a result, the temperature of node $b$ scanned by the oscillating laser can be higher than the melting temperature of TC4 titanium alloy to form a molten pool, which also increases the width of the molten pool. The temperature rising and dropping form of oscillation will also be transferred to the CFRTP 
surface to play a stirring role in the surface resin, thus promoting the flow of molten resin and a more uniform temperature distribution, and the dispersed heat will also contribute to a larger resin melting area at the interface.

\section{Experimental Results And Discussions}

In the experiment, the following process parameters are adopted: laser power of $2000 \mathrm{~W}$, scanning speed of $0.015 \mathrm{~m} / \mathrm{s}$, defocus amount of $+18 \mathrm{~mm}$ and the flow rate of protective gas of $30 \mathrm{~L} / \mathrm{min}$. In addition, the swing amplitude of the oscillating laser is $2 \mathrm{~mm}$ and the frequency is $100 \mathrm{~Hz}$. Fig. 11 presents the interface morphology of laser joining CFRTP/TC4 titanium alloy joints obtained under two laser scanning modes. According to Fig. 11 (a) and (c), the heat generated by two laser scanning modes will decompose part of the resin and produce bubbles. Then the bubble defects mainly exist in the resin on the CFRTP side of the joint interface and the filling resin in the surface microgrooves on the titanium alloy side. Proper heat input can cause a sufficient amount of resin to melt at the interface, and this heat input will also produce resin decomposition and generate bubbles near the interface. During the movement of bubbles with the flow of resin, the air pressure tension inside the bubble causes the bubble to expand and grow, and the pressure generated by the bubble expansion promotes the flow of the molten resin. So that the groove is almost filled with the molten resin, and then the interface between the resin and the titanium alloy is fully combined. In addition, since the resin fills up the groove, it is difficult for some bubbles to escape from the inside of the molten resin. After the laser joining, the bubbles that have not escaped remain at the interface as the resin cools, forming bubble defects of various sizes and mostly irregular shapes. As exhibited in the Fig. 11 (a), the resin filling morphology in the groove on the surface of TC4 titanium alloy presents relatively good, with the resin filling up the groove, although there are still a few unevenly sized bubble defects in the resin. In contrast, as presented in Fig. 11 (c), the resin filling morphology in the groove on the surface of TC4 titanium alloy presents poor, with a large number of large-size bubbles and incomplete fusion defects, which are caused by the high heat concentration from the linear laser. According to the previous temperature field simulation results, oscillating laser joining avoids local heat concentration and distributes the heat more evenly to the resin, so that more resin reaches the melting temperature and less resin reaches the thermal decomposition temperature, thus reducing the generation of bubbles. Linear laser joining produces a more concentrated heat input, which makes it easier for the resin to reach the decomposition temperature, and the generated bubbles have difficulty escaping from the inside of the molten resin, forming bubble defects. Excessive bubble defects will not only reduce the filling amount of resin, but also produce cracks, weakening the joining strength of the joint. In this paper, resin filling rate and porosity are introduced to quantitatively analyze the interface morphology characteristics of laser joining joints. Resin filling rate refers to the ratio of the area of resin filled into the groove to the area of the groove itself, which represents the amount of resin flowing into the groove. Porosity refers to the ratio of the area of bubbles near the interface to the area of the surface resin, which is used to describe the content of bubbles near the interface. The specific measurements are carried out by using image processing software and the results are as follows: when oscillating laser joining is adopted, the resin filling rate is $92.20 \%$ and the porosity is $3.78 \%$; When linear laser joining is 
adopted, the resin filling rate is $60.11 \%$ and the porosity is $32.89 \%$. It is obvious that the oscillating laser greatly reduces the generation of bubbles in the laser joining of CFRTP and TC4 titanium alloy, and effectively increases the filling amount of resin.

In the process of laser joining, a sufficient amount of resin melts at the joining interface under high heat input, and the molten resin comes into full contact with the titanium alloy under pressure, resulting in a high bonding force at the interface. However, at the same time, titanium alloy and resin expand and contract due to the rapid heating and cooling. The thermal physical properties of titanium alloy and resin are quite different, so the shrinkage degree of the two materials is different after laser joining, which is tend to produce tensile stress at the interface. The tensile stress at the interface competes with the interfacial bonding force. When the tensile stress at the interface is greater than the interfacial bonding force, the joining interface will be detached and fusion gaps will occur. Comparing the two figures in Fig. 11 (b) and (d), it is apparent that under the oscillating laser scanning mode, the resin at the edge of the groove on the surface of titanium alloy is filled tightly and no obvious defects such as bubbles and fusion gap are found. That is because the temperature rising and dropping form of oscillation dilutes the rapid change of temperature and also weakens the expansion and contraction of titanium alloy and resin, resulting in less tensile stress at the interface. However, under the linear laser scanning mode, the fusion morphology between the interface grooves and the filling resin presents poor, with small-sized fusion gaps. In this case, the balance between the tensile stress at the interface and the interfacial bonding force is broken. As more resin reaches the decomposition temperature, there is less molten resin that can be in full contact with the titanium alloy, and the interfacial bonding force is already low. In addition, the direct heat generated by linear laser joining also makes the titanium alloy and resin rise to a relatively high temperature quickly, and the shrinkage degree of the two materials during the cooling process varies greatly, resulting in the tensile stress at the interface being relatively high. The high tensile stress at the interface and low interfacial bonding force contribute to the appearance of fusion gaps.

The lap shear test method ASTM D3163-01 is employed with the computer-controlled testing equipment of UTM5000 to obtain the fracture load of the hybrid joint. The shear performance test equipment and results of laser joining CFRTP/TC4 titanium alloy joints under two laser scanning modes are displayed in Fig. 12. As is demonstrated in the figure, when the oscillating laser scanning mode is adopted, the fracture displacement of the tensile sample obtained by CFRTP and TC4 titanium alloy laser joining is $0.45 \mathrm{~mm}$, and the tensile strength of the sample is up to $24.48 \mathrm{MPa}$. However, when the traditional laser linear joining method is adopted, the fracture displacement of the sample is reduced to $0.33 \mathrm{~mm}$, which is reduced by $26.67 \%$. At the same time, the maximum loading force and the failure load of the sample joint also decrease, and the tensile strength of the sample decreases to $20.46 \mathrm{MPa}$, a decrease of $16.42 \%$. Laser scanning mode not only exercises considerable influence over the interface morphology, but also indirectly affects the joint strength. It is apparent that for laser joining CFRTP/TC4 titanium alloy joints when other process parameters remain relatively constant, the oscillating laser joining which produces better interface morphology could attain higher joining strength of the joint. 


\section{Conclusions}

In the present research, the numerical simulation and the experimental investigation on CFRTP/TC4 titanium alloy laser joining under oscillating laser joining mode and linear laser joining mode have been carried out. The following conclusions can be drawn:

1. The simulated temperature distribution shows good agreement with the experimental result, and the oscillating laser could produce wider molten pool. Compared with linear laser joining, the oscillating laser joining not only weakens the heat concentration and reduce thermal decomposition of resin, but also promotes a more uniform temperature distribution, increasing the melting area of the resin at the interface.

2. When oscillating laser joining is adopted, the resin filling rate is $92.20 \%$ and the porosity is $3.78 \%$. But when linear laser joining is adopted, the resin filling rate is $60.11 \%$ and the porosity is $32.89 \%$. As a result, the oscillating laser joining optimizes the interface morphology of laser joining CFRTP/TC4 titanium alloy joints with better resin filling and fewer bubble defects. Meanwhile, there are a large number of large-size bubbles in the filling resin and small-sized fusion gaps distributed at the interface grooves under the linear laser scanning mode.

3. The oscillating laser joining avoids local heat concentration and distributes the heat more evenly to the resin, so that more resin reaches the melting temperature while less resin reaches the thermal decomposition temperature, thus reducing the generation of bubbles. At the same time, the temperature rising and dropping form of oscillation dilutes the rapid change of temperature and also weakens the expansion and contraction of titanium alloy and resin, resulting in less tensile stress at the interface.

4. Compared with the traditional laser linear joining method, when other process parameters remain relatively constant, adopting the joining method with oscillating laser scanning mode could obtain higher quality joints with the joining strength of $24.48 \mathrm{MPa}$.

\section{Declarations}

\section{Funding}

The authors declare that no funds, grants, or other support were received during the preparation of this manuscript.

\section{Conflicts of interest}

The authors declare no competing interests.

\section{Availability of data and material}

Data and materials are available.

\section{Code availability}


Not applicable.

\section{Ethics approval}

Not applicable.

\section{Consent to participate}

Not applicable.

\section{Consent for publication}

All authors have read and agreed to the published version of the manuscript.

\section{Authors' contributions}

The welding experiment was conducted by Weiwen Chen and Feiyun Wang. The grinding and polishing of metallographic samples were completed by Hengchang Bu and Jiebang Luo. Data processing and manuscript preparation were led by Weiwen Chen with contributions from all authors.

\section{References}

1. N. Konchakova, F. Balle, F.J. Barth, R. Mueller, D. Eifler, P. Steinmann (2010) Finite element analysis of an inelastic interface in ultrasonic welded metal/fibre-reinforced polymer joints. Computational Materials Science 50(1):184-190. https://doi.org/10.1016/j.commatsci.2010.07.024

2. S. Berger, F. Oefele, M. Schmidt (2015) Laser transmission welding of carbon fiber reinforced thermoplastic using filler material-A fundamental study. Journal of Laser Applications 27(S2):S29009. https://doi.org/10.2351/1.4906391

3. Haipeng Wang, Yang Chen, Zaoyang Guo, Yingchun Guan (2019) Porosity Elimination in Modified Direct Laser Joining of Ti6Al4V and Thermoplastics Composites. Applied Sciences 9(3):411. https://doi.org/10.3390/app9030411

4. B. Arash, Q. Wang, V. K. Varadan (2014) Mechanical properties of carbon nanotube/polymer composites. Scientific Reports 4:6479. https://doi.org/10.1038/srep06479

5. Shangyu Liu, Jian Zhou, Yanqing Li, Xiaoyuan Zhang (2019) Using reaction heat of laser-induced AlTi-C interlayer to connect CFRTP/aluminum. Optics \& Laser Technology 113:365373. https://doi.org/10.1016/j.optlastec.2018.12.044

6. Yun Li, Xiaohong Zhan, Chuanyun Gao, Hongen Wang, Yang Yang (2019) Comparative study of infrared laser surface treatment and ultraviolet laser surface treatment of CFRP laminates. The International Journal of Advanced Manufacturing Technology 102(8). https://doi.org/10.1007/s00170-019-03368-z

7. Abhay K. Jha, Satish Kumar Singh, M. Swathi Kiranmayee, K. Sreekumar, P.P. Sinha (2010) Failure analysis of titanium alloy (Ti6Al4V) fastener used in aerospace application. Engineering Failure 
Analysis 17(6):1457-1465. https://doi.org/10.1016/j.engfailanal.2010.05.007

8. Navneet Khanna, J.P. Davim (2015) Design-of-experiments application in machining titanium alloys for aerospace structural components. Measurement 61:280-

290. https://doi.org/10.1016/j.measurement.2014.10.059

9. George Marsh (2014) Composites and metals - A marriage of convenience? Reinforced Plastics 58(2):38-42. https://doi.org/10.1016/S0034-3617(14)70108-0

10. Qiyu Gao, Yun Li, Hong-en Wang, Weiping Liu, Honglie Shen, Xiaohong Zhan (2019) Effect of Scanning Speed with UV Laser Cleaning on Adhesive Bonding Tensile Properties of CFRP. Applied Composite Materials 26(3):1-13. https://doi.org/10.1007/s10443-019-09768-4

11. Xianghu Tan, Jing Zhang, Jiguo Shan, Shanglu Yang, Jialie Ren (2015) Characteristics and formation mechanism of porosities in CFRP during laser joining of CFRP and steel. Composites Part B: Engineering 70:35-43. https://doi.org/10.1016/j.compositesb.2014.10.023

12. Hongliang Wang, Xingcheng Xiao, Guoxian Xiao, Hua-Tzu Fan, Jorge Arinez (2019) Laser Joining of Carbon-Fiber-Reinforced Polymer and Metal with High-Strength and Corrosion-Resistant Bonds. Procedia Manufacturing 34:42-48. https://doi.org/10.1016/j.promfg.2019.06.112

13. K.W. Jung, Y. Kawahito, M. Takahashi, S. Katayama (2011) Laser direct joining of carbon fibre reinforced plastic to stainless steel. Science and Technology of Welding and Joining 16(8):676680. https://doi.org/10.1179/1362171811Y.0000000060

14. K.W. Jung, Y. Kawahito, M. Takahashi, S. Katayama (2013) Laser direct joining of carbon fiber reinforced plastic to zinc-coated steel. Materials \& Design 47:179-

188. https://doi.org/10.1016/j.matdes.2012.12.015

15. K.W. Jung, Y. Kawahito, M. Takahashi, S. Katayama (2013) Laser direct joining of carbon fiber reinforced plastic to aluminum alloy. Journal of Laser Applications 25(3):530533. https://doi.org/10.2351/1.4794297

16. J.P. Bergmann, M. Stambke (2012) Potential of Laser-manufactured Polymer-metal hybrid Joints. Physics Procedia 39(9):84-91. https://doi.org/10.1016/j.phpro.2012.10.017

17. P. Amend, S. Pfindel, M. Schmidt (2013) Thermal Joining of Thermoplastic Metal Hybrids by Means Of Mono- and Polychromatic Radiation. Physics Procedia 41:98105. https://doi.org/10.1016/j.phpro.2013.03.056

18. E. Rodríguez-Vidal, J. Lambarri, C. Soriano, C. Sanz, G. Verhaeghe (2014) A Combined Experimental and Numerical Approach to the Laser Joining of Hybrid Polymer - Metal Parts. Physics Procedia 56:835-844. https://doi.org/10.1016/j.phpro.2014.08.101

19. Zhou Zhang, Jiguo Shan, Xianghu Tan, Jing Zhang (2017) Improvement of the laser joining of CFRP and aluminum via laser pre-treatment. The International Journal of Advanced Manufacturing Technology 90:3465-3472. https://doi.org/10.1007/s00170-016-9646-5

20. F. Lambiase, S. Genna (2017) Laser-assisted direct joining of AISI304 stainless steel with polycarbonate sheets: Thermal analysis, mechanical characterization, and bonds morphology. Optics \& Laser Technology 88:205-214. https://doi.org/10.1016/j.optlastec.2016.09.028 
21. F. Lambiase, S. Genna, R. Kant (2018) A procedure for calibration and validation of FE modelling of laser-assisted metal to polymer direct joining. Optics \& Laser Technology 98:363-

372. https://doi.org/10.1016/j.optlastec.2017.08.016

22. K. Van Der Straeten, A. Olowinsky, A. Gillner (2018) Laser-based plastic-metal-joining with selforganizing microstructures considering different load directions. Journal of Laser Applications 30:032401. https://doi.org/10.2351/1.5040616

23. Junke Jiao, Zifa Xu, Qiang Wang, Liyuan Sheng, Wenwu Zhang (2018) CFRTP and stainless steel laser joining: Thermal defects analysis and joining parameters optimization. Optics \& Laser Technology 103:170-176. https://doi.org/10.1016/j.optlastec.2018.01.023

24. Wang Tao, Xuan Su, Yanbin Chen, Ze Tian (2019) Joint formation and fracture characteristics of laser welded CFRP/TC4 joints. Journal of Manufacturing Processes 45:1-

8. https://doi.org/10.1016/j.jmapro.2019.05.028

25. Jianhui Su, Caiwang Tan, Zhuolun Wu, Laijun Wu, Xiangtao Gong, Bo Chen, Xiaoguo Song, Jicai Feng (2020) Influence of defocus distance on laser joining of CFRP to titanium alloy. Optics \& Laser Technology 124,106006. https://doi.org/10.1016/j.optlastec.2019.106006

26. Furat I. Hussein, Kareem N. Salloomi, E. Akman, K.I. Hajim, A. Demir (2017) Finite element thermal analysis for PMMA/st.st.304 laser direct joining. Optics \& Laser Technology 87:64-

71. https://doi.org/10.1016/j.optlastec.2016.07.017

27. F. Lambiase, S. Genna, R. Kant (2018) A procedure for calibration and validation of FE modelling of laser-assisted metal to polymer direct joining. Optics \& Laser Technology 98,363-

372. https://doi.org/10.1016/j.optlastec.2017.08.016

28. Junke Jiao, Qiang Wang, Feiya Wang, Shaoping Zan, Wenwu Zhang (2017) Numerical and experimental investigation on joining CFRTP and stainless steel using fiber lasers. Journal of Materials Processing Technology 240:362-369. https://doi.org/10.1016/j.jmatprotec.2016.10.013

29. Junke Jiao, Zifa Xu, Qiang Wang, Shaoping Zan (2018) Research on carbon fiber reinforced thermal polymer/stainless steel laser direct joining. Journal of Laser Applications 30(3):

032419. https://doi.org/10.2351/1.5040627

30. Kentaro Taki, Shuhei Nakamura, Tetsuo Takayama, Akihiko Nemoto, Hiroshi Ito (2016) Direct joining of a laser-ablated metal surface and polymers by precise injection molding. Microsystem Technologies 22(1):31-38. https://doi.org/10.1007/s00542-015-2640-2

31. André Heckert, Michael F. Zaeh (2014) Laser Surface Pre-treatment of Aluminium for Hybrid Joints with Glass Fibre Reinforced Thermoplastics. Physics Procedia 56:1171-

1181. https://doi.org/10.1016/j.phpro.2014.08.032

32. E. Rodríguez-Vidal, C. Sanz, J. Lambarri, I. Quintana (2018) Experimental investigation into metal micro-patterning by laser on polymer-metal hybrid joining. Optics \& Laser Technology 104:7382. https://doi.org/10.1016/j.optlastec.2018.02.003

33. Junke Jiao, Yiyun Ye, Shaohui Jia, Zifa Xu, Wentai Ouyang, Wenwu Zhang (2020) CFRTP -Al alloy laser assisted joining with a high speed rotational welding technology. Optics \& Laser Technology 
127:106187. https://doi.org/10.1016/j.optlastec.2020.106187

34. Florian Fetzer, Martin Sommer, Rudolf Weber, Jan-Philipp Weberpals, Thomas Graf (2018) Reduction of pores by means of laser beam oscillation during remote welding of AlMgSi. Optics and Lasers in Engineering 108:68-77. https://doi.org/10.1016/j.optlaseng.2018.04.012

35. Hengchang Bu, Yun Li, Hongyan Yang, Leilei Wang, Xiaohong Zhan (2020) Investigation of laser joining process of CFRTP and aluminum alloy. Materials and Manufacturing Processes 1-8. https://doi.org/10.1080/10426914.2020.1762205

\section{Figures}



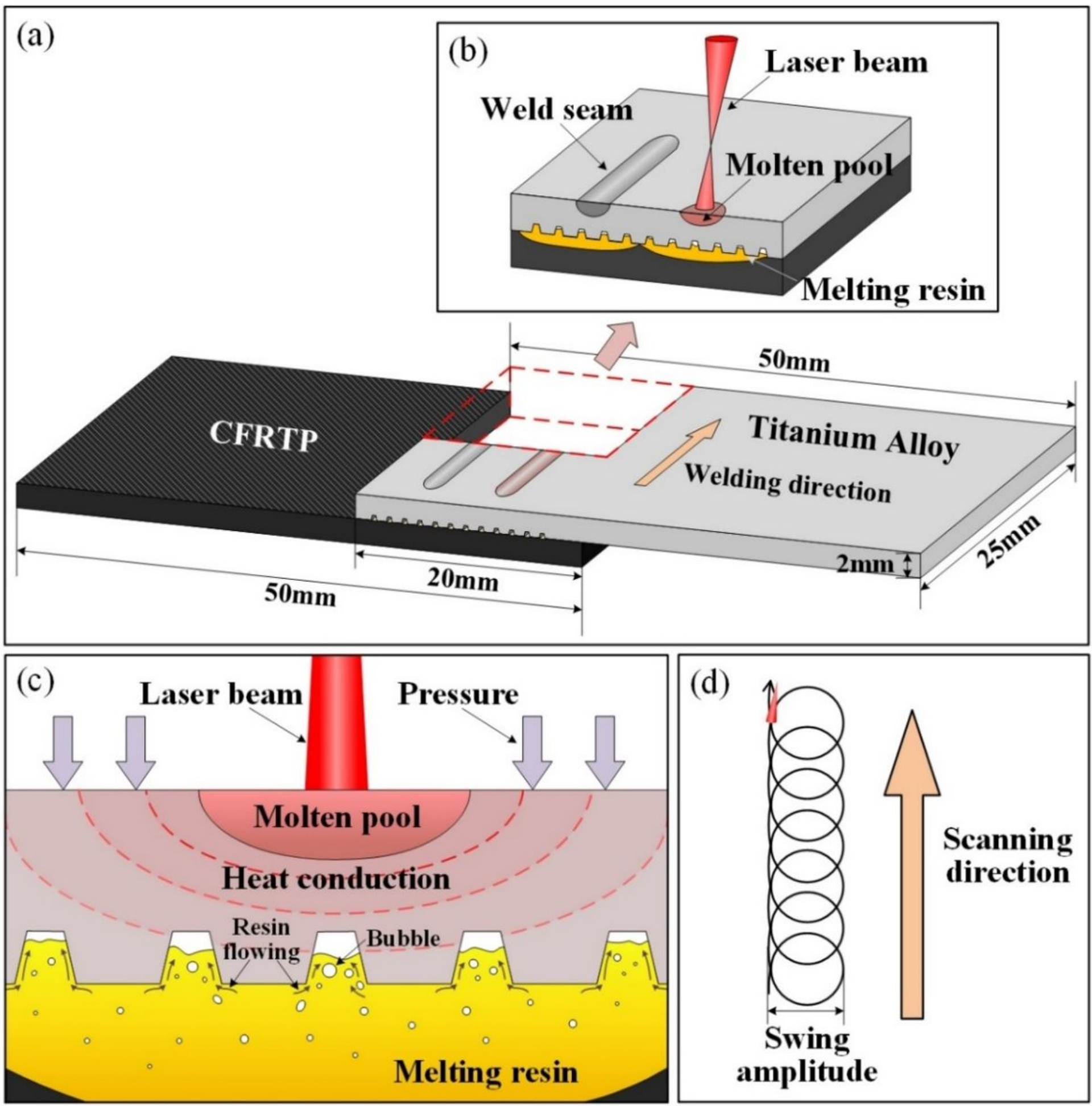

Figure 1

$<\mathrm{p}>$ The schematic diagram of laser joining process principle between CFRTP and TC4 titanium alloy: (a) The schematic diagram of laser scanning during laser joining; (b) A partially enlarged view of figure (a); (c) The schematic diagram of resin filling; (d) The trajectory of laser oscillation. $</ p>$ 


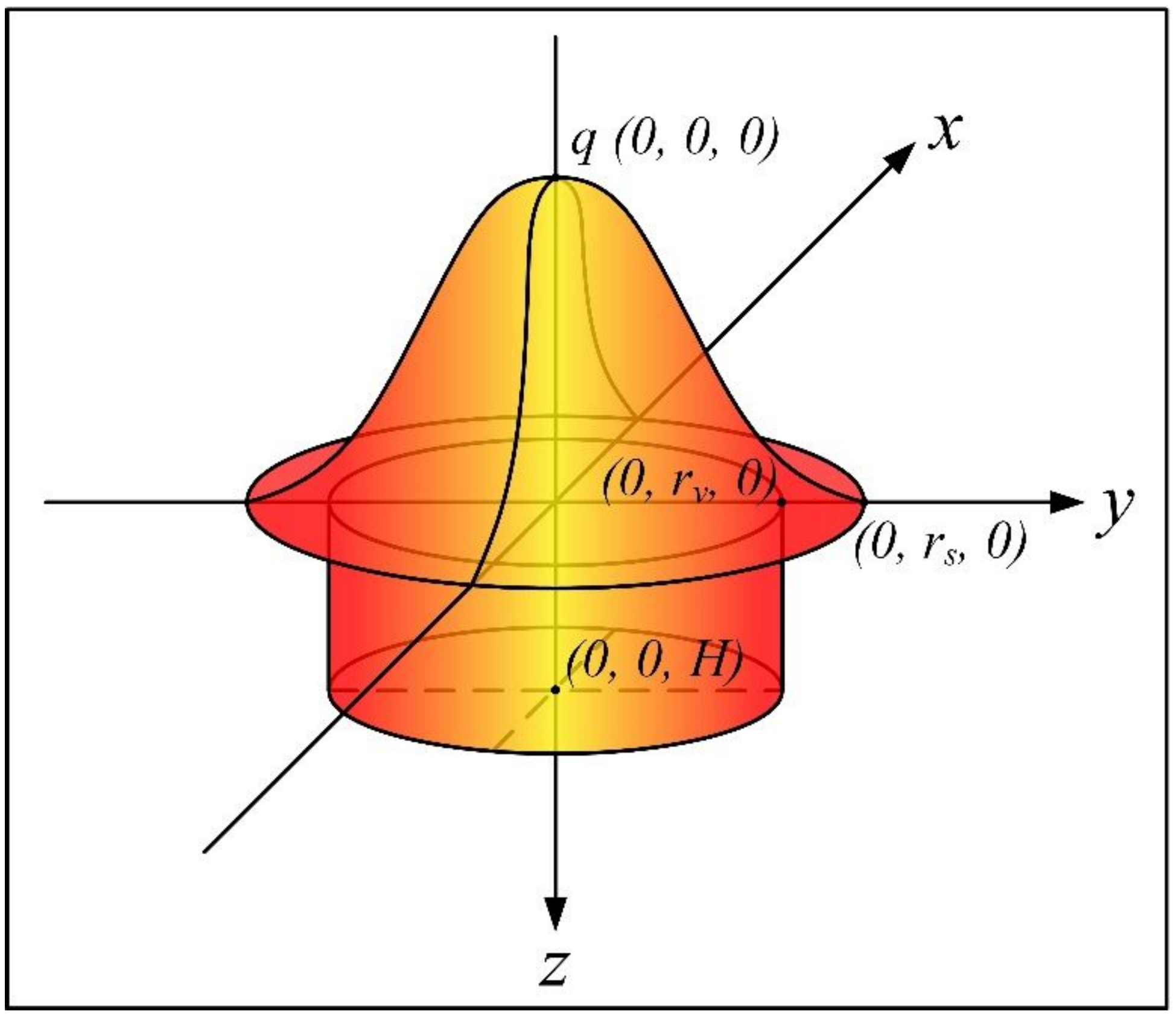

Figure 2

$<\mathrm{p}>$ The schematic diagram of composite heat source model of "Gaussian surface heat source + Gaussian cylindrical volumetric heat source". $</ p>$ 

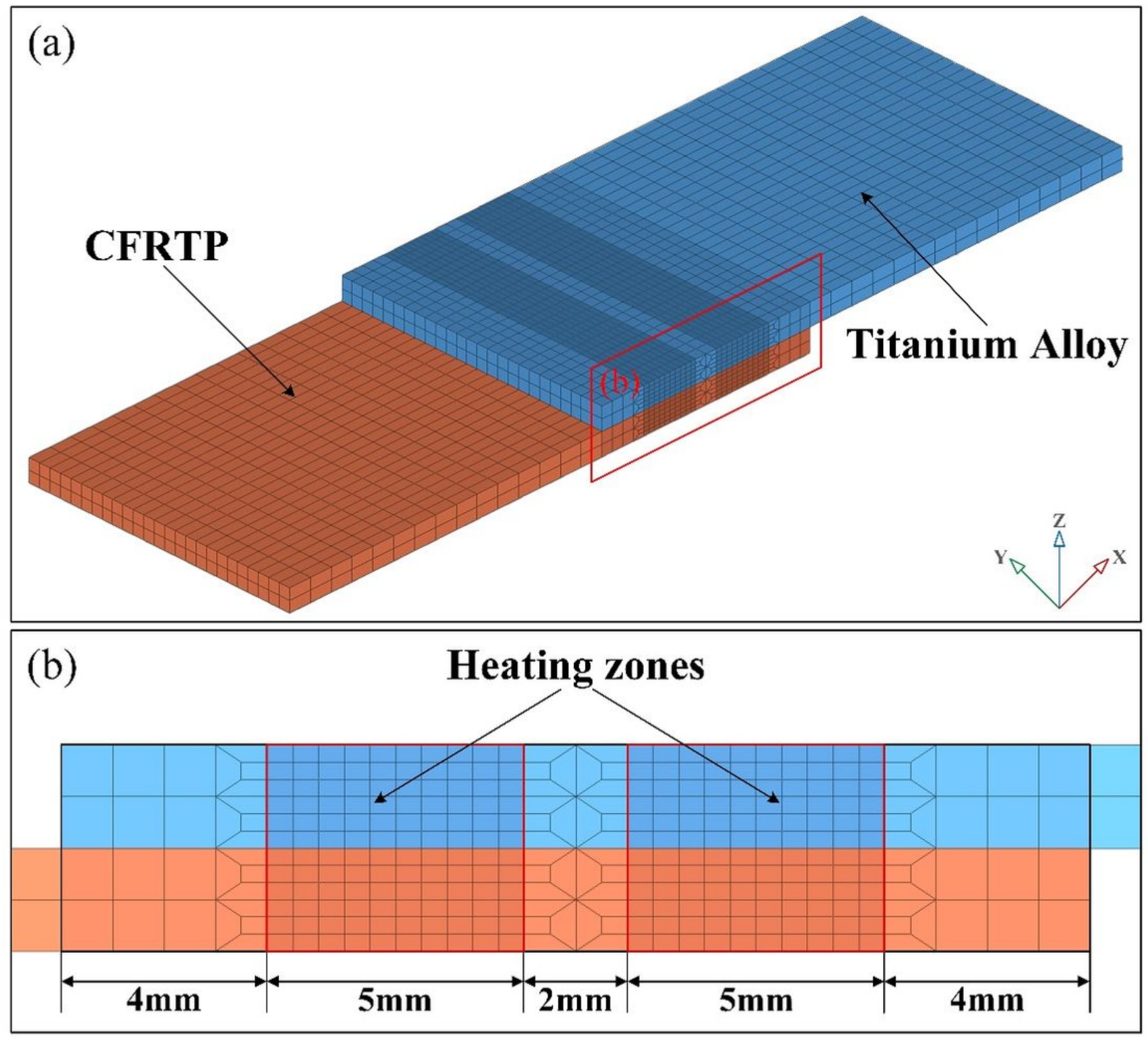

Figure 3

$<p>$ The mesh model of laser joining structure between CFRTP and TC4 titanium alloy: $</ p>p p>(a)$ The overall view of the mesh model; (b) A partially enlarged view of connection area. $</ p>$ 


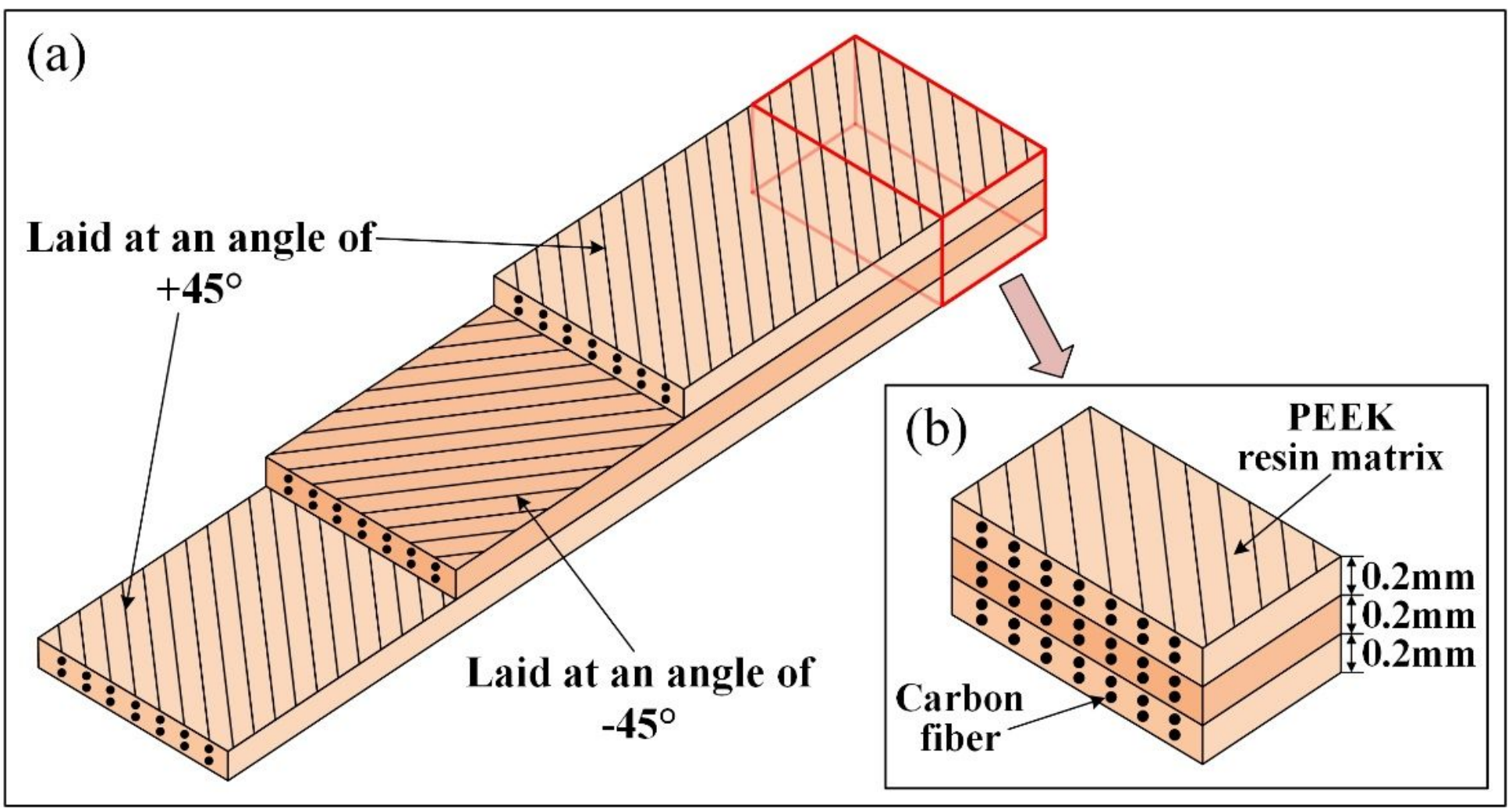

Figure 4

$<p>$ The schematic diagram of carbon fibers laying mode in CFRTP: (a) The overall view; (b) The schematic diagram of cross section. $</ p>$
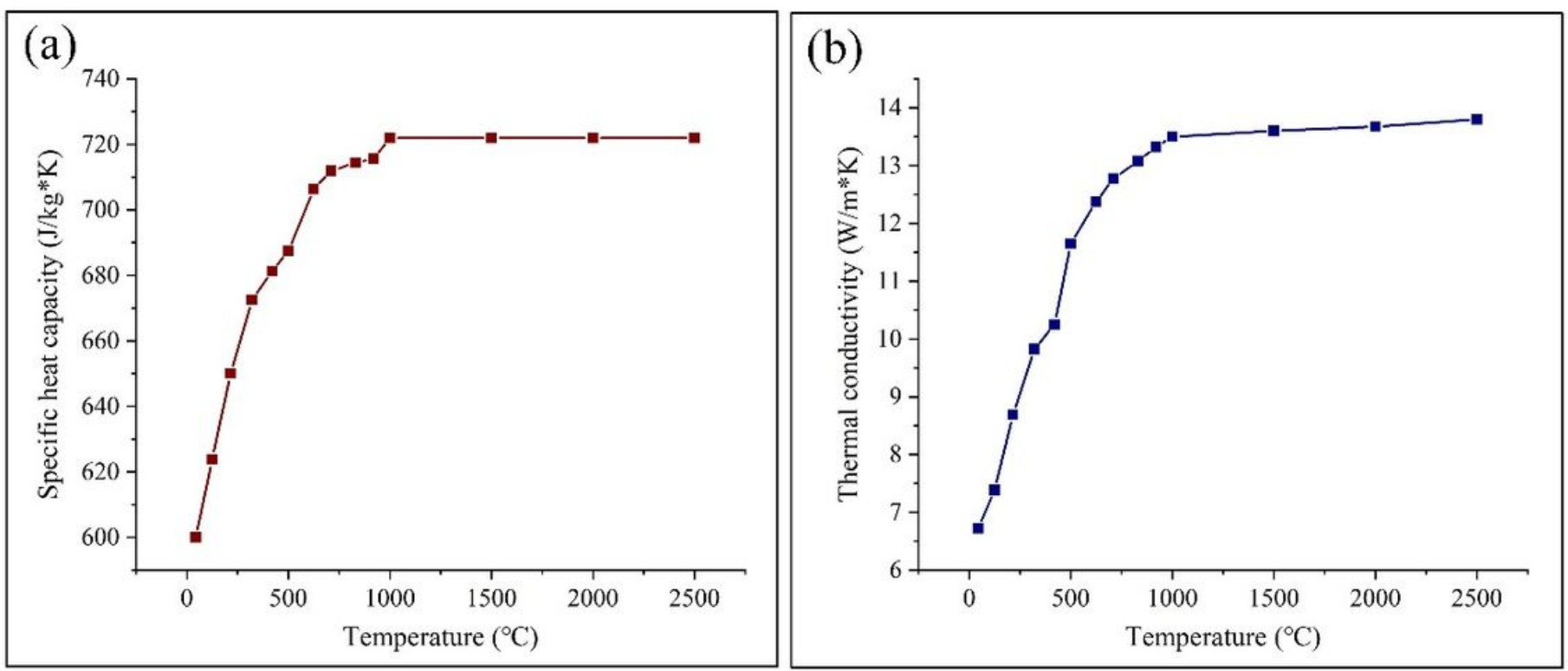

Figure 5

$<p>$ Thermophysical parameters of TC4 titanium alloy: (a) Specific heat capacity; (b) Thermal conductivity. $</ p>$ 


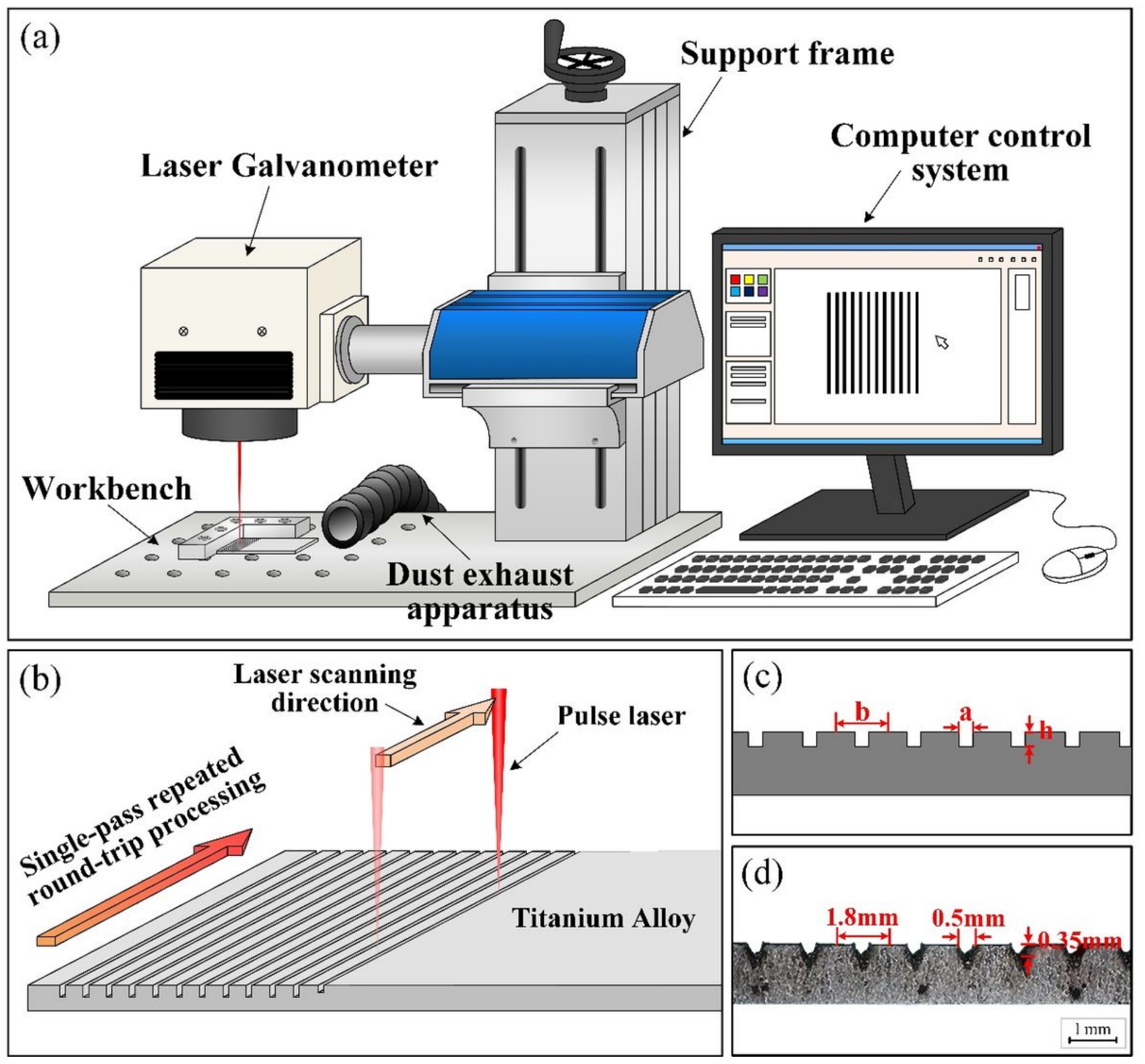

Figure 6

$<p>$ The schematic diagram of the laser processing process of TC4 titanium alloy surface microgrooves: (a) Laser processing equipment; (b) A partially enlarged view of the laser processing process; (c) (d) The model diagram and macro morphology diagram of TC4 titanium alloy surface after laser processing. $</ p>$ 


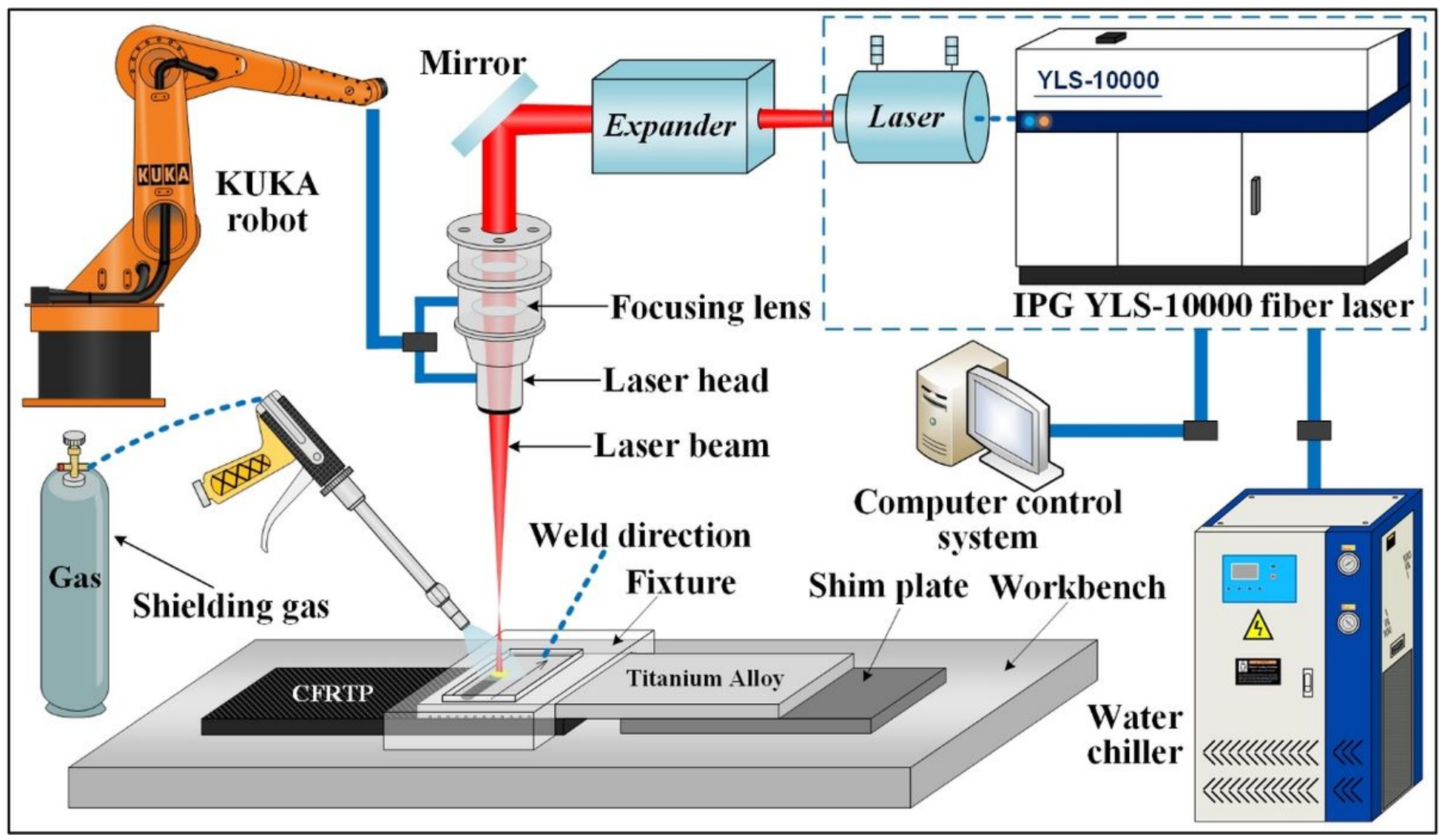

Figure 7

$<p>$ The schematic diagram of the laser joining process of CFRTP/TC4 titanium alloy. $</ p\rangle$ 


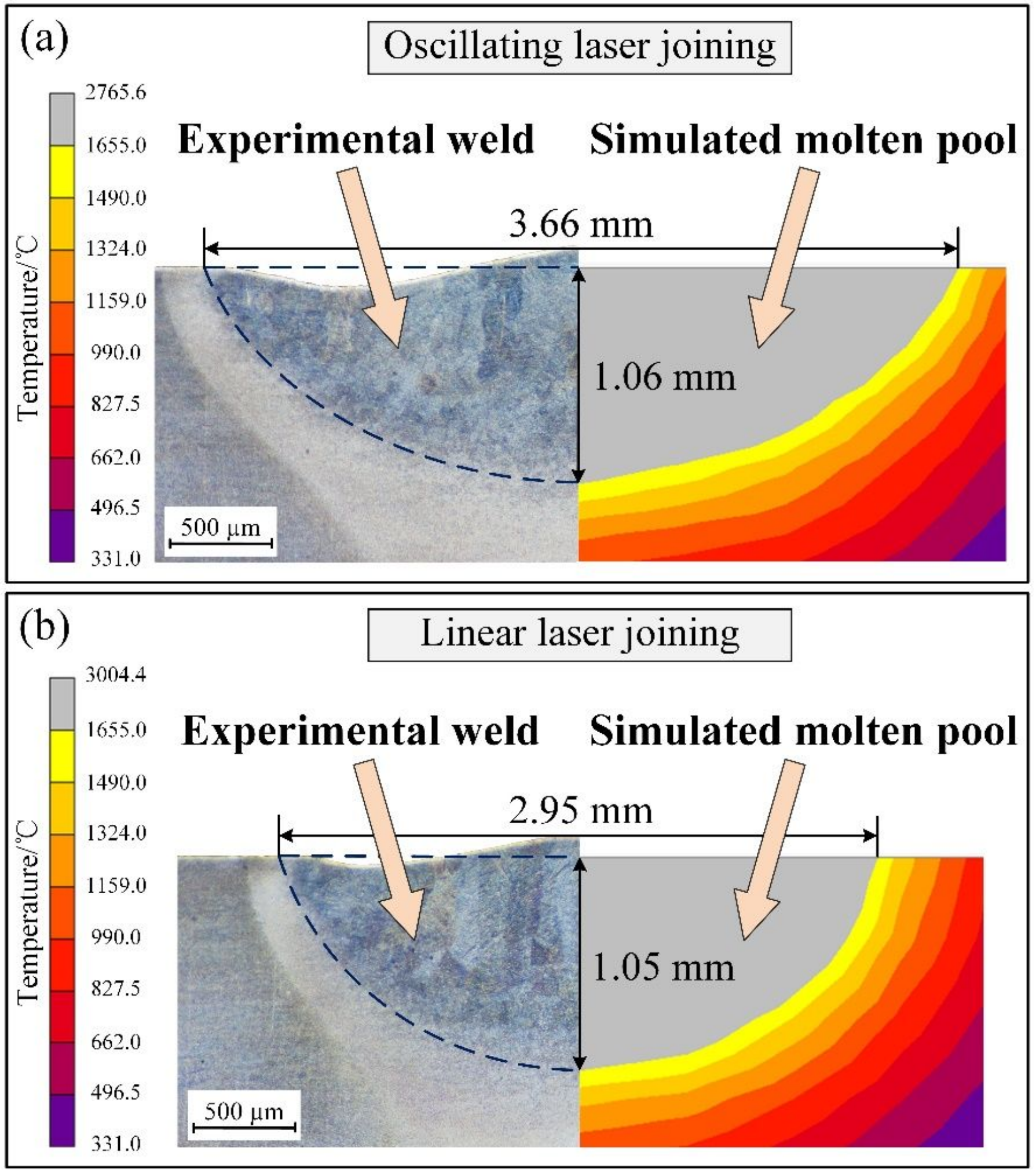

Figure 8

$<p>$ Experimental and simulated results of weld seam profile: (a) Oscillating laser joining; (b) Linear laser joining. $</ p>$ 

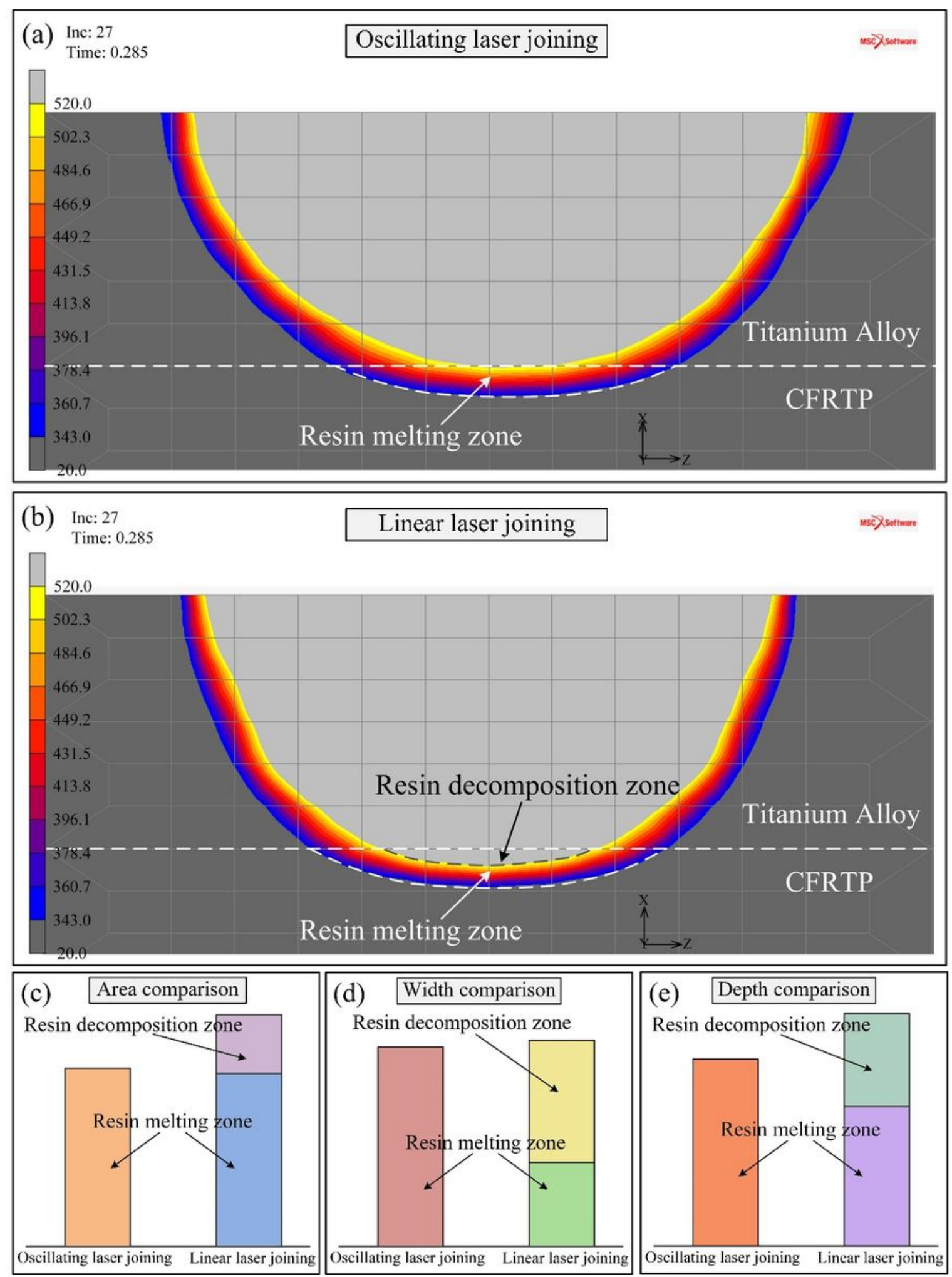

\section{Figure 9}

$<p>$ The simulated interface fusion zone at $t=0.285 \mathrm{~s}$ : (a) Oscillating laser joining; (b) Linear laser joining; (c) Area comparison of interface fusion zone; (d) Width comparison of interface fusion zone; (e) Depth comparison of interface fusion zone.</p> 


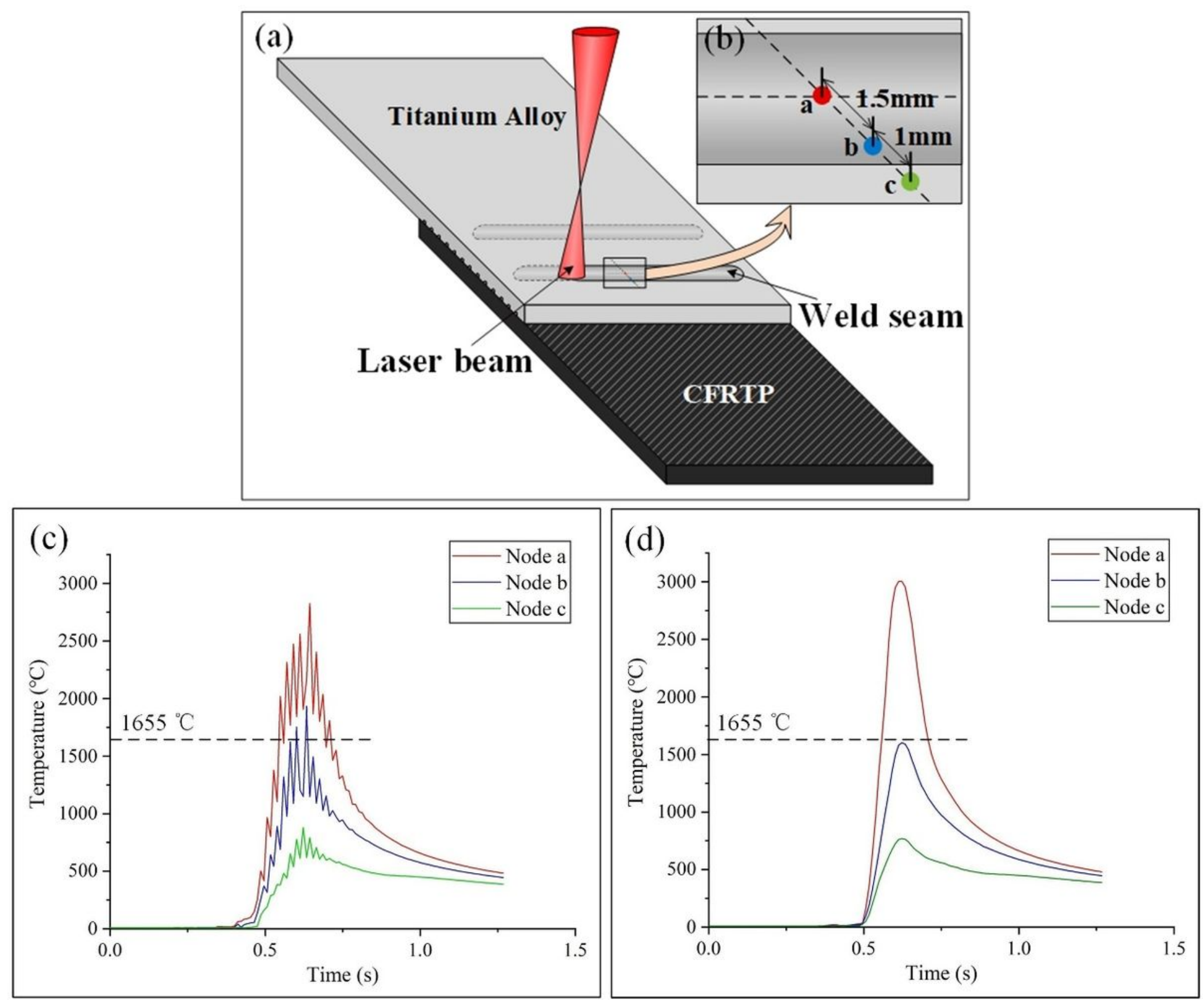

Figure 10

$<p>$ Variation of temperature on the TC4 titanium alloy surface: (a) The schematic diagram of node selection (b) A partially enlarged view of figure (a); (c) Oscillating laser joining; (d) Linear laser joining. $</ p>$ 

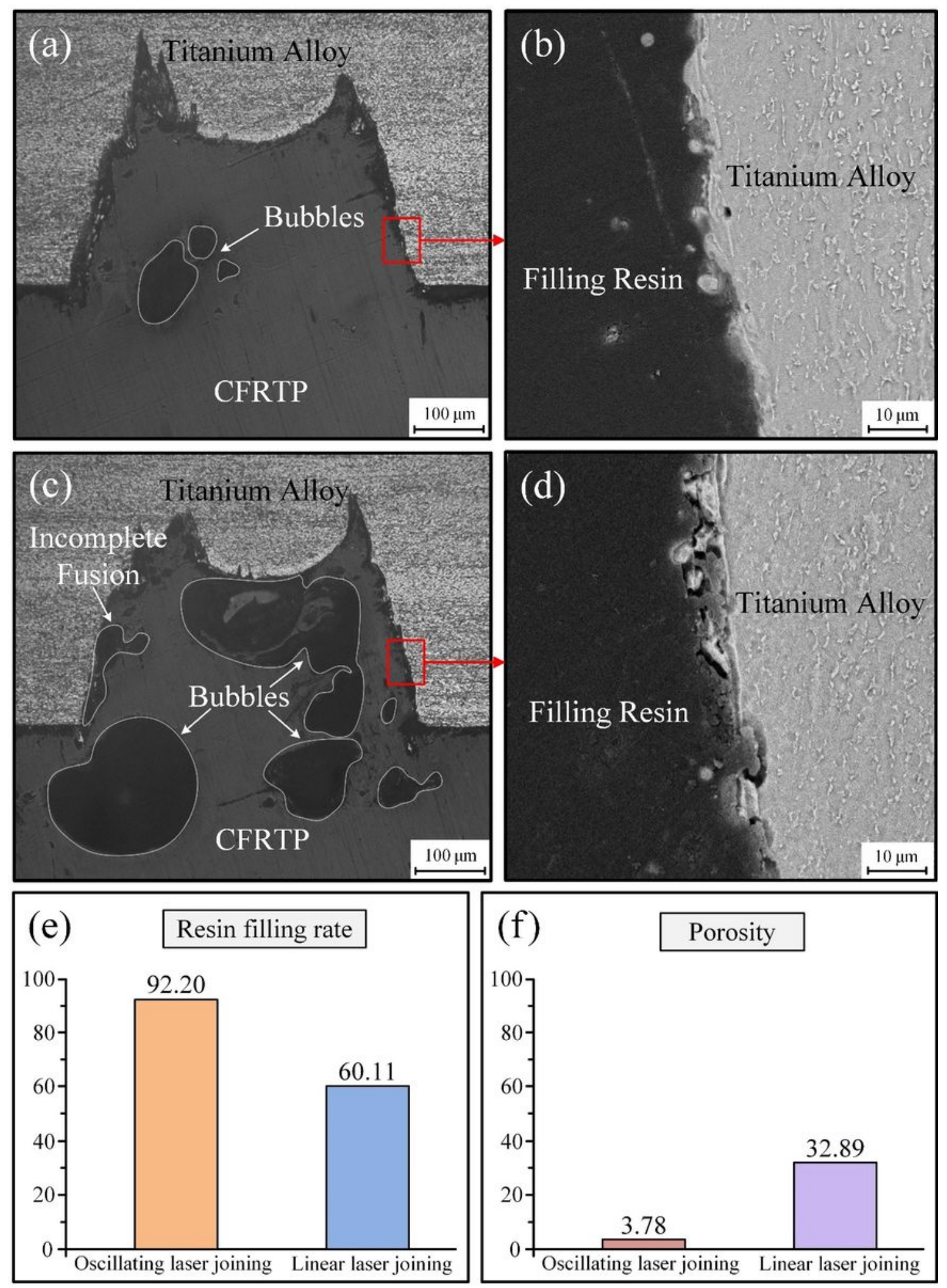

\section{Figure 11}

$<p>$ The interface morphology of laser joining CFRTP/TC4 titanium alloy joints: (a) (b) Oscillating laser joining; (c) (d) Linear laser joining; (e) Resin filling rate in two laser scanning modes; (f) Porosity in two laser scanning modes. $</ p>$ 


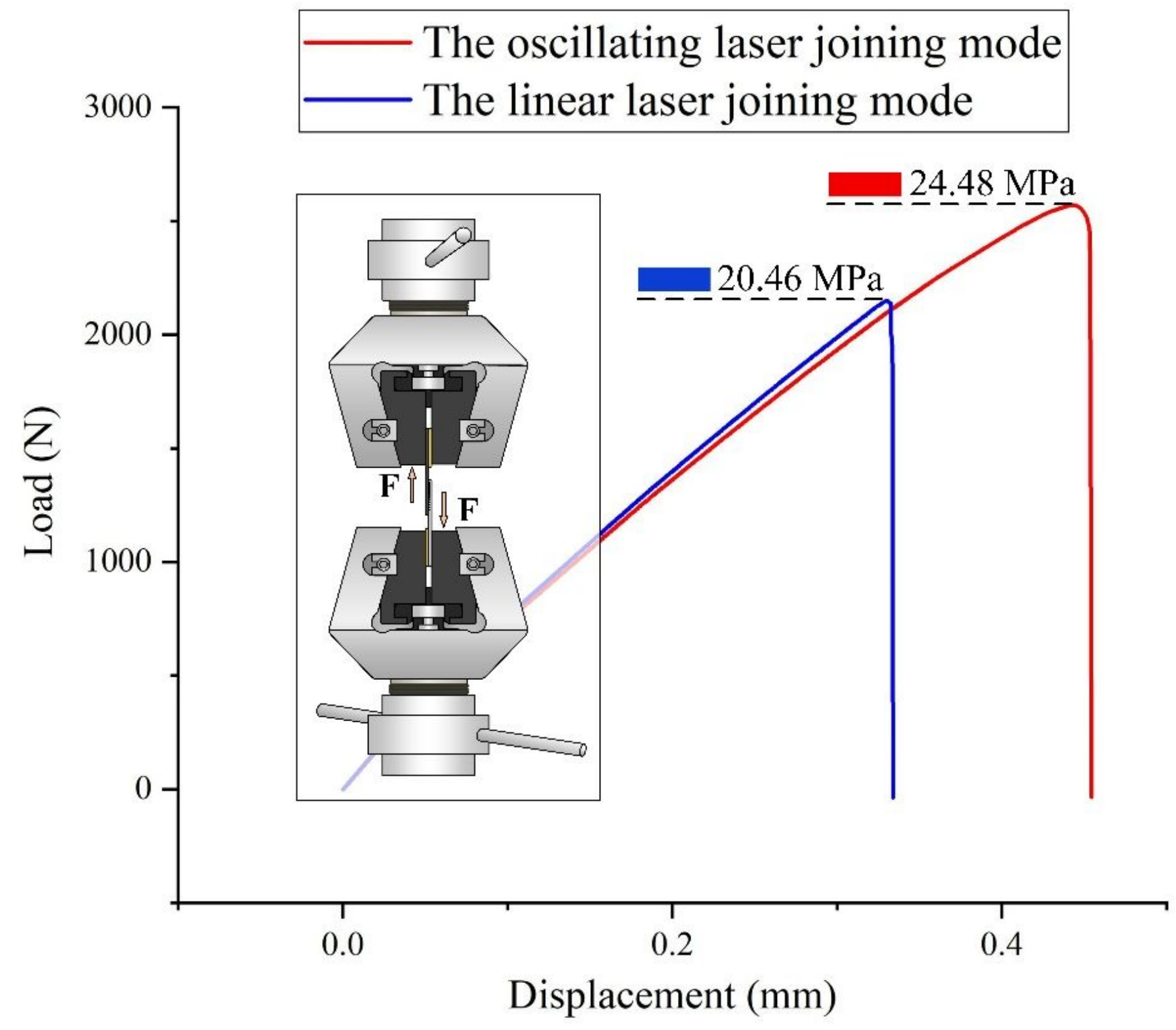

Figure 12

$<\mathrm{p}>$ The $<$ strong $></$ strong $>$ shear performance test equipment and results of laser joining CFRTP/TC4 titanium alloy joints. $</ p>$ 